The Federal Reserve BanK of KANSAs City ECONOMIC RESEARCH DEPARTMENT

Learning about Monetary

Policy Rules when Labor

Market Search and Matching Frictions Matter

Takushi Kurozumi and Willem Van Zandweghe December 2010

RWP 10-14 


\title{
Learning about Monetary Policy Rules when Labor Market Search and Matching Frictions Matter
}

\author{
Takushi Kurozumi $^{\dagger} \quad$ Willem Van Zandweghe
}

November 2010

RWP 10-14

\begin{abstract}
This paper examines implications of incorporating labor market search and matching frictions into a sticky price model for determinacy and E-stability of rational expectations equilibrium (REE) under interest rate policy. When labor adjustment takes place solely at the extensive margin, forecast-based policy that meets the Taylor principle is likely to induce indeterminacy and E-instability, regardless of whether it is strictly or flexibly inflation targeting. When labor adjustment takes place at both the extensive and intensive margins, the strictly inflation-forecast targeting policy remains likely to induce indeterminacy, but it generates a unique E-stable fundamental REE as long as the Taylor principle is satisfied. These results suggest that introducing the search and matching frictions alter determinacy properties of the strictly inflation-forecast targeting policy, but not its E-stability properties in the presence of the intensive margin of labor.
\end{abstract}

Keywords: Labor market search and matching frictions; Forecast-based interest rate policy; Indeterminacy; E-stability; Extensive and intensive margins of labor

JEL classification: E24, E52

* This paper is a revision of part of Kurozumi and Van Zandweghe (2008). The authors are grateful for discussions and comments from James Bullard, Miguel Casares, Kai Christoffel, Daniele Coen-Pirani, Riccardo DiCecio, John Duffy, Huberto Ennis, Marvin Goodfriend, Michael Krause, Thomas Lubik, Bennett McCallum, and Alexander Wolman, as well as participants at Midwest Macroeconomics Meetings 2007, EEA-ESEM 2007, Federal Reserve System Conference on Macroeconomics 2008, NASMES 2008, Learning Week 2008, BIS, Bank of Canada, ECB, Kansas City Fed, Richmond Fed, Portland State University, University of Notre Dame, and West Virginia University. The views expressed herein are those of the authors and should not be interpreted as those of the Bank of Japan, the Federal Reserve Bank of Kansas City or the Federal Reserve System.

$\nmid$ Bank of Japan, 2-1-1 Nihonbashi Hongokucho, Chuo-ku, Tokyo 103-8660, Japan. Tel.: +81 33279 1111; fax: +81 35205 2055. E-mail address: takushi.kurozumi@boj.or.jp

\$Federal Reserve Bank of Kansas City, 1 Memorial Drive, Kansas City, MO 64198, USA. Tel.: +1 816 881 2766; fax: +1 816881 2199. E-mail address: willem.vanzandweghe@kc.frb.org 


\section{Introduction}

Recent monetary policy literature has incorporated labor market search and matching frictions along the lines of Mortensen and Pissarides (1994) into sticky price models and has studied their implications for optimal monetary policy (e.g. Thomas, 2008; Faia, 2009; Ravenna and Walsh, 2010; Tang, 2010) and for equilibrium determinacy under interest rate policy (Kurozumi and Van Zandweghe, 2010). ${ }^{1}$ In the latter paper, we find that strictly inflation-forecast targeting interest rate policy almost always induces indeterminacy when it meets the Taylor principle. ${ }^{2}$

This paper examines the implications for both determinacy and E-stability of rational expectations equilibrium (REE) under interest rate policy. As McCallum (2007) points out, E-stability is very closely linked with least-squares learnability (i.e. stability under least-squares learning), and this learnability is arguably a necessary property for an REE to be plausible as an equilibrium for the model at hand. For a broad class of linear models with expectations (including the model of this paper), an REE is least-squares learnable when it is E-stable and non-explosive. If an REE is not E-stable, it is not stable under least-squares learning. Therefore, E-stability is an essential condition for an REE to be regarded as plausible.

This paper has two main results. First, when the labor input in production is adjusted solely at the extensive margin (i.e. variation in employment), the strictly inflation-forecast targeting interest rate policy is likely to induce E-instability as well as indeterminacy. Specifically, this policy generates a unique E-stable fundamental REE only if the Taylor principle is satisfied and the policy coefficient on the inflation forecast is either not large or very large. ${ }^{3}$ Only a policy coefficient in these two intervals succeeds in guiding temporary equilibria under nonrational expectations toward the unique E-stable REE. Since the intermediate interval that yields indeterminate E-unstable REE contains all empirically plausible values of the policy

\footnotetext{
${ }^{1}$ For business cycle studies using sticky price models with labor market search and matching frictions, see e.g. Walsh (2005), Krause and Lubik (2007), Sveen and Weinke (2009), Trigari (2009), and Van Zandweghe (2010).

${ }^{2}$ After the working-paper version of this paper (Kurozumi and Van Zandweghe, 2008) was released, two related works emerged, both of which employ the Blanchard and Galí (2010) sticky price model with hiring costs. Tesfaselassie and Schaling (2009) show the importance of the size of the hiring costs for the policy response to unemployment that ensures determinacy and E-stability. Rannenberg (2009) introduces skill decay during unemployment into the model and analyzes its implications for the Taylor principle.

${ }^{3}$ Throughout the paper, the term "fundamental" refers to Evans and Honkapohja (2001) minimal state variable (MSV) solutions to linear RE models to distinguish them from McCallum (1983) original MSV solution.
} 
coefficient, the indeterminacy induced by the strictly inflation-forecast targeting policy is a critical issue even from the perspective of E-stability or least-squares learnability of REE. ${ }^{4}$ Moreover, when the forecast-based interest rate policy is flexibly inflation targeting (i.e. it responds to an unemployment forecast in addition to the inflation forecast), it remains very unlikely to generate a determinate E-stable REE or a unique E-stable fundamental REE. ${ }^{5}$ This result is in contrast to that of Bullard and Mitra (2002), who show that, in the presence of a frictionless labor market, such policy yields a determinate E-stable REE or a unique E-stable fundamental REE as long as the Taylor principle is satisfied.

Second, when labor adjustment takes place at both the extensive and intensive margins (i.e. changes in both employment and hours per worker), the strictly inflation-forecast targeting policy remains likely to induce indeterminacy. However, this policy generates a unique E-stable fundamental REE as long as the Taylor principle is satisfied, as in line with Bullard and Mitra (2002). Therefore, in the presence of both labor margins, the indeterminacy induced by the strictly inflation-forecast targeting policy is no longer a critical issue from the perspective of E-stability or least-squares learnability of fundamental REE. ${ }^{6}$ Moreover, the flexibly inflationforecast targeting policy is likely to generate a determinate E-stable REE.

These two results suggest that introducing the labor market search and matching frictions alter determinacy properties of the strictly inflation-forecast targeting interest rate policy, but not its E-stability properties in the presence of the intensive margin of labor.

The remainder of the paper proceeds as follows. Section 2 describes a sticky price model with labor market search and matching frictions. Section 3 presents the analysis of E-stability as well as determinacy under interest rate policy. This section first considers the model in which labor adjustment takes place solely at the extensive margin, and then turns to the model with both the extensive and intensive margins. Section 4 conducts a sensitivity analysis with respect to values of structural parameters of the model. Section 5 concludes.

\footnotetext{
${ }^{4}$ When interest rate policy targets the contemporaneous inflation rate, determinacy and E-stability of REE are generated as long as the Taylor principle is satisfied.

${ }^{5}$ A sufficiently high degree of interest rate smoothing, with a policy coefficient on the inflation forecast that meets the Taylor principle, yields a determinate E-stable REE.

${ }^{6}$ This paper does not examine E-stability of non-fundamental REE such as sunspot equilibria, which may exist in cases of indeterminacy. For E-stability analysis of these REE, see e.g. Honkapohja and Mitra (2004), Carlstrom and Fuerst (2004), and Evans and McGough (2005), who all use associated models with frictionless labor markets. We leave E-stability analysis of non-fundamental REE in our model for future work.
} 


\section{$2 \quad$ A sticky price model with labor market search and matching frictions}

The model is a sticky price model with search and matching frictions in the labor market. It is in line with recent business cycle studies, such as Walsh (2005), Krause and Lubik (2007), Sveen and Weinke (2009), Trigari (2009), and Van Zandweghe (2010), and recent monetary policy studies, such as Thomas (2008), Faia (2009), Ravenna and Walsh (2010), Tang (2010), and Kurozumi and Van Zandweghe (2010). The economy is inhabited by four types of agents. First, the representative household consists of a continuum of members. Some members are employed and others search for jobs, but all members provide each other with insurance against unemployment risk by making joint consumption and saving decisions. Second, the representative wholesale firm hires workers in the matching market, and uses a labor-only technology to produce homogeneous goods. Third, retail firms differentiates the wholesale goods at no cost and set prices of their products on a staggered basis as in Calvo (1983) and Yun (1996). Last, the monetary authority sets its policy rate according to a Taylor (1993) style rule.

\subsection{Labor market}

The labor market is characterized by search and matching frictions along the lines of Mortensen and Pissarides (1994). Unemployed workers search for jobs, and firms pay a flow cost $P_{t} \gamma$ to maintain a job opening in period $t$. At the beginning of the period, a proportion $\rho \in(0,1)$ of existing matches $n_{t-1}$ is exogenously destroyed before matching starts. Newly matched workers $m_{t}$ become productive instantaneously, and thus the law of motion of employment is

$$
n_{t}=(1-\rho) n_{t-1}+m_{t}
$$

The matching friction faced by workers and firms is represented by a constant returns to scale matching function that determines the number of new matches between job searchers and vacancies as

$$
m_{t}=\psi u_{t}^{\xi} v_{t}^{1-\xi}
$$

where $\psi>0, \xi \in(0,1)$ measures the search elasticity of new matches, and $u_{t}, v_{t}$ are the number of searching workers and vacancies. With the labor force normalized to one, the number of job searchers is given by

$$
u_{t}=1-(1-\rho) n_{t-1}
$$


while the unemployment rate is defined as

$$
U_{t}=1-n_{t}
$$

The job finding probability $p_{t}$ and the vacancy filling probability $q_{t}$ are given by

$$
\begin{aligned}
p_{t} & \equiv \frac{m_{t}}{u_{t}}=\psi \theta_{t}^{1-\xi}, \\
q_{t} & \equiv \frac{m_{t}}{v_{t}}=\psi \theta_{t}^{-\xi},
\end{aligned}
$$

where the ratio of vacancies to searchers

$$
\theta_{t}=\frac{v_{t}}{u_{t}}
$$

measures the labor market tightness. Thus, when the labor market tightens, a worker is more likely to find a job and a firm is less likely to fill a vacancy.

\subsection{Representative household}

The representative household consists of a continuum of household members. Each period, a household member may either be unemployed or employed, in which case she works $h_{t}$ hours. To avoid distributional issues, it is assumed as in Merz (1995) that employed and unemployed household members pool consumption. This representative household purchases consumption goods $c_{t}$ and holds nominal one-period bonds $B_{t}$ that earn the gross nominal interest rate $R_{t}$ in the subsequent period so as to maximize expected lifetime utility

$$
\max E_{0} \sum_{t=0}^{\infty} \beta^{t}\left[\frac{\left(c_{t}-b c_{t-1}\right)^{1-\sigma}}{1-\sigma} g_{t}+\chi_{u}\left(1-n_{t}\right)-\chi_{e} n_{t} \frac{h_{t}^{1+\mu}}{1+\mu}\right]
$$

subject to the budget constraint

$$
P_{t} c_{t}+B_{t}=P_{t} w_{t} h_{t} n_{t}+D_{t}+B_{t-1} R_{t-1}
$$

Here, $\beta \in(0,1)$ is the subjective discount factor, $\sigma>0$ measures relative risk aversion, $\mu \geq 0$ is the inverse of the labor supply elasticity, $b \in[0,1]$ is the degree of internal habit persistence in

consumption preferences, $\chi_{u}, \chi_{e} \geq 0$ are scale coefficients of leisure utility and labor disutility, and $g_{t}$ is a shock to consumption preferences that follows a stationary first-order autoregressive process with the autoregressive coefficient $\rho_{g} \in(-1,1)$ and the white noise $\varepsilon_{g t}$,

$$
\log g_{t}=\rho_{g} \log g_{t-1}+\varepsilon_{g t}
$$


Family income consists of wage income $P_{t} w_{t} h_{t} n_{t}$ from employment and other income $D_{t}$. Consumption $c_{t}=\left[\int_{0}^{1} c_{t}(j)^{(\epsilon-1) / \epsilon} d j\right]^{\epsilon /(\epsilon-1)}$ is a composite of differentiated goods produced by retail firms, with the substitution elasticity $\epsilon>1$. Thus, cost-minimizing demand for good $j$ is given by $c_{t}(j)=\left(P_{t}(j) / P_{t}\right)^{-\epsilon} c_{t}$, where the aggregate price index satisfies

$$
P_{t}=\left(\int_{0}^{1} P_{t}(j)^{\epsilon-1} d j\right)^{\frac{1}{\epsilon-1}} .
$$

The first-order conditions for optimal consumption and optimal bond holdings are given by

$$
\begin{aligned}
\lambda_{t} & =\left(c_{t}-b c_{t-1}\right)^{-\sigma} g_{t}-\beta b E_{t}\left(c_{t+1}-b c_{t}\right)^{-\sigma} g_{t+1}, \\
\lambda_{t} & =\beta E_{t} \lambda_{t+1} \frac{R_{t}}{\pi_{t+1}},
\end{aligned}
$$

where $\lambda_{t}$ is the marginal utility of consumption and $\pi_{t}=P_{t} / P_{t-1}$ is the gross inflation rate. Taking account of the employment law of motion gives rise to the asset value of employment

$$
W_{t}=w_{t} h_{t}-z_{t}+\beta(1-\rho) E_{t} \frac{\lambda_{t+1}}{\lambda_{t}}\left(1-p_{t+1}\right) W_{t+1},
$$

where the flow value of unemployment

$$
z_{t}=\frac{1}{\lambda_{t}}\left(\chi_{u}+\chi_{e} \frac{h_{t}^{1+\mu}}{1+\mu}\right)
$$

consists of the consumption value of leisure and foregone work effort. The household's marginal value of a family member matched with a job equals the sum of the premium of the real wage over the flow value of unemployment and the discounted expected future value. The latter is discounted by the time-varying discount factor that values future consumption in present terms and by the probability that the job is destroyed and no new job is found. Labor hours per worker is determined as the outcome of bargaining between a worker and a wholesale firm.

\subsection{Representative wholesale firm}

The representative wholesale firm uses a production technology that is linear in total hours worked

$$
y_{t}=n_{t} h_{t}
$$

as in e.g. Sveen and Weinke (2009) and Trigari (2009). This firm chooses employment $n_{t}$ and vacancies $v_{t}$ so as to maximize profits by selling its product at the relative price $m c_{t}$ to retail firms under perfect competition. Thus, the firm solves the problem

$$
\max E_{0} \sum_{t=0}^{\infty} \beta^{t} \frac{\lambda_{t}}{\lambda_{0}}\left[\left(m c_{t}-w_{t}\right) h_{t} n_{t}-\gamma v_{t}\right]
$$


subject to the employment law of motion (1). The first-order conditions for profit maximization include

$$
\begin{aligned}
J_{t} & =\left(m c_{t}-w_{t}\right) h_{t}+\beta(1-\rho) E_{t} \frac{\lambda_{t+1}}{\lambda_{t}} J_{t+1}, \\
J_{t} & =\frac{\gamma}{q_{t}},
\end{aligned}
$$

where $J_{t}$ denotes the Lagrange multiplier on (1), which represents the firm's asset value of a filled job. The profit maximization thus requires this asset value to be equal to the sum of the current return and the discounted expected future value and to the average cost of filling a job opening. This average cost is the flow cost of posting a vacancy times the number of vacancies posted in order to fill one job, which is the inverse of the vacancy filling probability.

The costly job creation gives rise to a surplus from a match, $S_{t}=J_{t}+W_{t}$, which is split between the matched worker and firm through Nash bargaining. The real wage is thus set in order to provide the worker and the firm with a share of the match surplus $W_{t}=\eta S_{t}$ and $J_{t}=(1-\eta) S_{t}$, respectively, where $\eta \in(0,1)$ denotes the worker's relative bargaining power. The resulting real wage equation is

$$
w_{t} h_{t}=\eta\left(m c_{t} h_{t}+\beta(1-\rho) E_{t} \frac{\lambda_{t+1}}{\lambda_{t}} p_{t+1} \frac{\gamma}{q_{t+1}}\right)+(1-\eta) z_{t} .
$$

A job entails compensation for a fraction $\eta$ of the revenue and the expected saving of hiring costs that the match generates, in addition to a fraction $1-\eta$ of the foregone flow value of unemployment.

A matched worker and firm also choose the number of labor hours per worker so as to maximize the joint surplus of the match. This yields

$$
\chi_{e} \frac{h_{t}^{\mu}}{\lambda_{t}}=m c_{t} .
$$

Hours per worker are chosen to set the marginal rate of substitution between consumption and leisure equal to the marginal revenue product of labor. Thus, hours per worker are allocated efficiently, as in the frictionless labor market that is considered by Bullard and Mitra (2002).

\subsection{Retail firms}

There is a continuum of retail firms $j \in[0,1]$, each of which produces one unit of differentiated good $j$ from one unit of wholesale goods and sells the quantity $Y_{t}(j)$ of good $j$ to households under monopolistic competition. Cost minimization implies that each retail firm's real marginal 
cost is equal to the wholesale goods' real price $m c_{t}$. Then, facing households' demand $Y_{t}(j)=$ $c_{t}(j)=\left(P_{t}(j) / P_{t}\right)^{-\epsilon} c_{t}$, each retail firm chooses its profit-maximizing price subject to Calvo (1983) and Yun (1996) style price stickiness. That is, each period a fraction $\alpha \in[0,1)$ of retail firms does not reoptimize price and instead adjusts it for steady-state gross inflation $\pi$, while the remaining fraction $1-\alpha$ of firms faces the problem

$$
\max _{P_{t}(j)} E_{t} \sum_{k=0}^{\infty}(\alpha \beta)^{k} \frac{\lambda_{t+k}}{\lambda_{t}}\left(\frac{P_{t}(j) \pi^{k}}{P_{t+k}}-m c_{t+k}\right)\left(\frac{P_{t}(j) \pi^{k}}{P_{t+k}}\right)^{-\epsilon} c_{t+k} .
$$

The first-order condition for optimal price setting is

$$
P_{t}(j)=\frac{\epsilon}{\epsilon-1} \frac{E_{t} \sum_{k=0}^{\infty}\left(\alpha \beta \pi^{-\epsilon}\right)^{k} \lambda_{t+k} P_{t+k}^{\epsilon} c_{t+k} m c_{t+k}}{E_{t} \sum_{k=0}^{\infty}\left(\alpha \beta \pi^{1-\epsilon}\right)^{k} \lambda_{t+k} P_{t+k}^{\epsilon-1} c_{t+k}} .
$$

\subsection{Monetary authority}

The monetary authority conducts interest rate policy that adjusts the policy rate in response to either a forecast of the future inflation and unemployment rates or to the contemporaneous inflation and unemployment rates and contains policy rate smoothing

$$
R_{t}=\left(R_{t-1}\right)^{\phi_{R}}\left[R\left(\frac{E_{t} \pi_{t+i}}{\pi}\right)^{\phi_{\pi}}\left(\frac{1-E_{t} U_{t+i}}{1-U}\right)^{\phi_{U}}\right]^{1-\phi_{R}}, \quad i=0,1
$$

where $R$ is the steady-state nominal interest rate, $\phi_{R} \in[0,1)$ is the degree of policy rate smoothing, and $\phi_{\pi}, \phi_{U}$ are non-negative policy coefficients on the inflation and unemployment rates. These policy specifications are referred to as outcome-based if $i=0$ and forecast-based if $i=1$.

\subsection{Log-linearization of equilibrium conditions and calibration}

A rational expectations equilibrium (REE) is a set of processes for all the endogenous variables satisfying (1)-(19), the aggregate resource constraint $y_{t}=Y_{t}+\gamma v_{t}$, and the market clearing condition $Y_{t}(j)=c_{t}(j)$ for each retail good $j \in[0,1]$, which implies $Y_{t}=\Delta_{t} c_{t}$, where $\Delta_{t} \equiv$

$\int_{0}^{1}\left(P_{t}(j) / P_{t}\right)^{-\epsilon} d j$ measures relative price dispersion across retail goods. Log-linearizing these 
equilibrium conditions around the steady state and rearranging the resulting equations yields

$$
\begin{aligned}
\hat{R}_{t} & =\phi_{R} \hat{R}_{t-1}+\left(1-\phi_{R}\right)\left[\phi_{\pi} E_{t} \hat{\pi}_{t+i}+\phi_{U}(1-U) E_{t} \hat{n}_{t+i}\right], i=0,1, \\
\hat{\pi}_{t} & =\beta E_{t} \hat{\pi}_{t+1}+\kappa \hat{m} c_{t} \\
\hat{\lambda}_{t} & =E_{t} \hat{\lambda}_{t+1}+\hat{R}_{t}-E_{t} \hat{\pi}_{t+1} \\
\hat{\lambda}_{t} & =-\frac{\sigma}{(1-b)(1-\beta b)}\left[\hat{c}_{t}-b \hat{c}_{t-1}-\beta b\left(E_{t} \hat{c}_{t+1}-b \hat{c}_{t}\right)\right]+\frac{1-\beta b \rho_{g}}{1-\beta b} \hat{g}_{t}, \\
h \hat{y}_{t} & =(h-\rho \gamma / q) \hat{c}_{t}+(\rho \gamma / q) \hat{v}_{t} \\
\hat{\theta}_{t} & =\hat{v}_{t}+\frac{(1-\rho)(1-U)}{1-(1-\rho)(1-U)} \hat{n}_{t-1}, \\
\hat{n}_{t} & =(1-\rho) \hat{n}_{t-1}+\rho\left(\hat{v}_{t}-\xi \hat{\theta}_{t}\right) \\
\xi \hat{\theta}_{t} & =\frac{(1-\eta)}{\gamma / q}\left(m c h \hat{m} c_{t}+z \hat{\lambda}_{t}\right)+\beta(1-\rho)\left[(\xi-\eta p) E_{t} \hat{\theta}_{t+1}-(1-\eta p)\left(\hat{R}_{t}-E_{t} \hat{\pi}_{t+1}\right)\right], \\
\hat{h}_{t} & =\frac{1}{1+\mu}\left(m c_{t}+\hat{\lambda}_{t}\right) \\
\hat{y}_{t} & =\hat{n}_{t}+\hat{h}_{t}
\end{aligned}
$$

where the hat on a variable denotes its percentage deviation from the steady-state value, and $\kappa \equiv(1-\alpha)(1-\alpha \beta) / \alpha>0$ is the real marginal cost elasticity of inflation. In this system the unemployment rate $U_{t}$, the number of searching workers $u_{t}$, the job finding probability $p_{t}$, the vacancy filling probability $q_{t}$, and the hourly wage $w_{t}$ have been substituted by (3)-(6) and (16), respectively.

Table 1 contains a quarterly baseline calibration of the model. As in the monetary policy literature, the discount factor is set at $\beta=0.99$, the risk aversion at $\sigma=1$, the habit persistence at $b=0$, the substitution elasticity at $\epsilon=10$, and the probability of no price reoptimization at $\alpha=0.67$. The steady-state hours per worker are normalized to $h=1$, and the labor supply elasticity is equal to $1 / \mu=0.7$, following Hall (2009). Regarding the labor market parameters, the worker's relative bargaining power of $\eta=0.5$ and the search elasticity of matches of $\xi=0.5$ are common values adopted in the labor market search literature. The steady-state flow value of unemployment of $z=0.7$ is an intermediate value in a wide range considered in the recent literature, in line with Hall and Milgrom (2008). The steady-state job finding rate $p=m / u$ is obtained from the steady-state conditions of (1) and (4). The job destruction rate and the steady-state unemployment rate are set respectively at $\rho=0.1$ and $U=1-n=0.06$, and these two parameters determine the steady-state job finding probability of $p=0.61$. The 
steady-state vacancy filling rate $q$ is obtained from the steady-state conditions of (14)-(16) as

$$
q=\gamma \frac{1-\beta(1-\rho)(1-\eta p)}{(1-\eta)(m c h-z)} .
$$

The flow cost of vacancy posting of $\gamma=0.18$ is chosen to target the steady-state job filling rate at $q=0.7^{7}$

\section{Analysis of E-stability}

In the model presented above, we examine implications of labor market search and matching frictions for determinacy and E-stability under interest rate policy. This section first considers the model in which labor adjustment takes place solely at the extensive margin. We then turn to the model with both the extensive and intensive margins.

\subsection{Methodology}

Before proceeding to results of the E-stability analysis, we present the methodology. Following the literature on learning in macroeconomics (e.g. Evans and Honkapohja, 2001), this paper takes the so-called "Euler equation" approach suggested by Honkapohja et al. (2003): the rational expectations operator $E_{t}$ is replaced with a possibly non-rational one $\hat{E}_{t}$ in the system of $(20)-(29)$. This system can be reduced to a system of the form

$$
F x_{t}=G \hat{E}_{t} x_{t+1}+H k_{t-1}+J g_{t},
$$

where $x_{t}$ is a vector that contains non-predetermined variables and $k_{t}$ is a vector that contains predetermined variables. Then, fundamental RE solutions to system (30) are given by

$$
x_{t}=\bar{c}+\bar{\Phi} k_{t-1}+\bar{\Gamma} g_{t}
$$

where the coefficient matrices are determined by

$$
\bar{c}=0, \quad G \bar{\Phi} e \bar{\Phi}=F \bar{\Phi}-H, \quad \bar{\Gamma}=\left\{F-G\left(\rho_{g} I+\bar{\Phi} e\right)\right\}^{-1} J
$$

where $e$ is a selection matrix that satisfies the relation $k_{t}=e x_{t}$ and $I$ denotes a conformable identity matrix. Note that $\bar{\Gamma}$ is uniquely determined given a $\bar{\Phi}$, but $\bar{\Phi}$ is not generally uniquely determined, which induces multiplicity of fundamental REE.

\footnotetext{
${ }^{7}$ Determinacy and E-stability conditions on interest rate policy will be invariant to the value of $\gamma$, since this parameter enters the system of log-linearized equilibrium conditions (20)-(29) only via the steady-state match value $\gamma / q$.
} 
Following Section 10.5 of Evans and Honkapohja (2001), E-stability of fundamental REE is investigated. ${ }^{8}$ Corresponding to fundamental RE solutions (31), all agents are assumed to be endowed with a perceived law of motion (PLM) of $x_{t}$

$$
x_{t}=c+\Phi k_{t-1}+\Gamma g_{t}
$$

Using a forecast from the PLM and the relation $k_{t}=e x_{t}$ to substitute $\hat{E}_{t} x_{t+1}$ out of (30) leads to an actual law of motion (ALM) of $x_{t}$

$$
x_{t}=F^{-1} G(I+\Phi e) c+F^{-1}(H+G \Phi e \Phi) k_{t-1}+F^{-1}\left\{J+G\left(\rho_{g} I+\Phi e\right) \Gamma\right\} g_{t}
$$

provided that $F$ is invertible. Then, a mapping $T$ from the PLM (32) to the ALM (33) can be defined by

$$
T(c, \Phi, \Gamma)=\left(F^{-1} G(I+\Phi e) c, F^{-1}(H+G \Phi e \Phi), F^{-1}\left\{J+G\left(\rho_{g} I+\Phi e\right) \Gamma\right\}\right) .
$$

For a fundamental RE solution $(\bar{c}, \bar{\Phi}, \bar{\Gamma})$ to be E-stable, the matrix differential equation

$$
\frac{d}{d \tau}(c, \Phi, \Gamma)=T(c, \Phi, \Gamma)-(c, \Phi, \Gamma)
$$

must have local asymptotic stability at the solution, that is, all eigenvalues of three matrices, $D T_{c}(\bar{c}, \bar{\Phi}), D T_{\Phi}(\bar{\Phi}), D T_{\Gamma}(\bar{\Phi}, \bar{\Gamma})$, have real parts less than one. Since

$$
\begin{aligned}
D T_{c}(c, \Phi) & =F^{-1} G(I+\Phi e), \\
D T_{\Phi}(\Phi) & =F^{-1} G(e \Phi I+\Phi e), \\
D T_{\Gamma}(\Phi, \Gamma) & =F^{-1} G\left(\rho_{g} I+\Phi e\right),
\end{aligned}
$$

the following lemma can be obtained.

Lemma 1 Suppose that the coefficient matrix $F$ is invertible. A fundamental REE is E-stable if and only if all eigenvalues of three matrices, $F^{-1} G(\varphi I+\bar{\Phi} e), \varphi \in\left\{1, \rho_{g}, e \bar{\Phi}\right\}$, have real parts less than one.

\footnotetext{
${ }^{8}$ System (30) contains at least one predetermined variable and thus it is possible to consider two learning environments, which are studied respectively in Sections 10.3 and 10.5 of Evans and Honkapohja (2001). One environment allows agents to use current endogenous variables in expectation formation, whereas another does not. This paper shows only E-stability analysis with the latter environment, as in Bullard and Mitra (2002), Kurozumi (2006), and Kurozumi and Van Zandweghe (2008). This is because the former induces a problem with simultaneous determination of the expectations and current endogenous variables, which is critical to equilibrium under non-rational expectations as indicated by Evans and Honkapohja (2001) and Bullard and Mitra (2002).
} 
With this lemma, E-stability of fundamental REE is numerically investigated, since it seems impossible to analytically solve the matrix equation for $\bar{\Phi}$ in fundamental RE solutions (31). As pointed out by McCallum (1998), distinct fundamental REE are obtained for different orderings of stable generalized eigenvalues of the matrix pencil for system (30).

\subsection{The model with extensive margin only}

In the model with the extensive margin only, the hours per worker condition (17) is replaced with $h_{t}=h$. Correspondingly, in the system of log-linearized equilibrium conditions (20)-(29), the production function (29) is replaced with $\hat{y}_{t}=\hat{n}_{t}$ and the hours per worker condition (28) is omitted.

First, the strictly inflation-forecast targeting interest rate policy (i.e. $i=1$ and $\phi_{U}=\phi_{R}=0$ in $(20)$ ) is considered. In the presence of the labor market search and matching frictions, such policy ensures determinacy of REE only in the narrow interval of the policy coefficient on the inflation forecast $1<\phi_{\pi}<1.04$. The policy coefficient that fails to satisfy the Taylor principle $\left(0 \leq \phi_{\pi} \leq 1\right)$ and the one that satisfies this principle and exceeds a certain threshold value $\left(\phi_{\pi}>1.04\right)$ make REE indeterminate. This indeterminacy is reported by another paper of ours (Kurozumi and Van Zandweghe, 2010). As this paper argues, the indeterminacy induced by the policy coefficient that satisfies the Taylor principle is due to a vacancy channel of monetary policy that stems from the search and matching frictions and that makes inflation expectations self-fulfilling. Such frictions result in firms' sluggish adjustment of employment. As a result, interest rate policy is transmitted by the vacancy channel in addition to the conventional aggregate demand channel that is the only channel in the absence of the labor market frictions. But these two channels have opposing effects on inflation. Whereas the aggregate demand channel leads a higher real interest rate to reduce inflation, the vacancy channel causes a rise in the real interest rate to increase inflation. ${ }^{9}$ This makes inflation expectations self-fulfilling

\footnotetext{
${ }^{9}$ This is because a real interest rate rise, by dampening consumption demand, reduces firms' current vacancy posting and hence lowers the level of employment available for production in current and subsequent periods. Hence, the interest rate rise lowers future output supply. At the same time, such a rate rise prompts households to substitute current with future consumption, and thus firms expect consumption demand to recover after its current decline. From this expected rise in future demand and the diminished future supply, firms anticipate a strong expansion of future vacancy posting. This raises expected future real marginal cost via an equilibrium job creation condition, and hence expected future inflation via the New Keynesian Phillips curve. Therefore, the vacancy channel leads a rise in the real interest rate to increase expected future inflation.
} 
under policy responses solely to the inflation forecast that meet the Taylor principle, and thereby induces indeterminacy.

The strictly inflation-forecast targeting policy generates a unique E-stable fundamental REE only if the policy coefficient on the inflation forecast lies in one of two intervals, which both satisfy the Taylor principle: $1<\phi_{\pi}<1.34$ and $\phi_{\pi}>13.97$. Only the policy coefficient in these two intervals succeeds in guiding temporary equilibria under non-rational expectations toward the unique E-stable REE. Because the intermediate interval $1.34 \leq \phi_{\pi} \leq 13.97$ contains all empirically relevant values of the policy coefficient (e.g. the estimate of $\phi_{\pi}=2.15$ by Clarida et al. (2000) for the Volcker-Greenspan period), the indeterminacy induced by the strictly inflation-forecast targeting policy is a critical issue even from the perspective of E-stability or least-squares learnability of REE.

This result is in contrast to that of Bullard and Mitra (2002), who examine an associated model with a frictionless labor market to show that the strictly inflation-forecast targeting policy is likely to ensure determinacy and guarantees E-stability as long as it meets the Taylor principle. In the presence of the labor market search and matching frictions, the vacancy channel emerges and reduces the guiding effect of the demand channel. As a result, no fundamental REE is E-stable if the policy coefficient on the inflation forecast lies in the intermediate interval between the two intervals that yields indeterminate E-unstable REE.

Figure 1 investigates whether a policy that is flexibly inflation-forecast targeting (i.e. $i=1$, $\phi_{U}>0$, and $\phi_{R}=0$ in (20)) or contains policy rate smoothing (i.e. $i=1, \phi_{U}=0$, and $\phi_{R}>0$ in (20)) is more likely to ensure determinacy of REE and E-stability of fundamental REE (FREE). These policies are motivated by empirical studies such as Clarida et al. (1998, 2000), who use them as a good description of actual monetary policy conducted in industrialized countries. ${ }^{10}$

The left panel of Figure 1 shows that, with a policy response to the inflation forecast that meets the Taylor principle, a policy response to the unemployment forecast does not mitigate the indeterminacy. As the coefficient on the unemployment forecast increases, the upper bound of the interval of the coefficient on the inflation forecast that ensures determinacy becomes

\footnotetext{
${ }^{10}$ These studies focus on policy responses to output rather than unemployment, although Clarida et al. (2000) also estimate policy rules with the unemployment rate. However, in the model in which labor adjustment takes place only at the extensive margin, percent changes in output are reflected to a large extent in percentage point changes in the unemployment rate, because labor is the only production input. Therefore, policies that respond to output would have similar implications for E-stability as those that respond to unemployment.
} 
smaller. As a result, for any policy response to the unemployment forecast greater than 0.32 , any policy response to the inflation forecast that satisfies the Taylor principle fails to ensure determinacy. ${ }^{11}$ The small region of the policy coefficients $\left(\phi_{\pi}, \phi_{U}\right)$ that ensures determinacy also ensures E-stability. In addition, an adjacent region of the policy coefficients generates indeterminacy and a unique E-stable fundamental REE, but this region is also small. Moreover, when the policy responds to the inflation forecast so that the Taylor principle is satisfied, very aggressive policy responses to the unemployment forecast can generate E-stability. However, in these cases there are multiple E-stable fundamental REE, and thus the issue of equilibrium multiplicity remains unresolved. Thus, the flexibly inflation-forecast targeting policy is not a good policy from the perspective of determinacy or E-stability.

As shown in the right panel of Figure 1, with a policy response to the inflation forecast that meets the Taylor principle, a sufficiently high degree of policy rate smoothing yields a determinate E-stable REE. Intuitively, this is because the feedback from the past policy rate smoothes the change in the current policy rate in response to a shift in the inflation forecast, which dampens the resulting change in the real interest rate and hence the change in consumption. Since employment can now adjust to consumption demand despite the labor market frictions, this weakens the effect of the vacancy channel. The right panel of Figure 1 provides an explanation for why the U.S. economy has not shown excessive volatility in recent decades in which Orphanides and Wieland (2008) indicate that the U.S. monetary policy has been forecast-based. From a normative perspective, it provides an argument in favor of a policy with interest rate smoothing.

When interest rate policy is outcome-based (i.e. $i=0$ in (20)), the Taylor principle ensures determinacy and E-stability of REE, regardless of whether the policy is strictly or flexibly inflation targeting. This is in line with the result of Bullard and Mitra (2002) obtained in an associated model with a frictionless labor market. Policy rate smoothing also yields a determinate E-stable REE as long as the Taylor principle is satisfied. Intuitively, the policy

\footnotetext{
${ }^{11}$ By contrast, another paper of ours (Kurozumi and Van Zandweghe, 2010) reports that the policy response to an unemployment forecast widens the interval of the policy coefficient on an inflation forecast that ensures determinacy. The difference between these results can be attributed to the presence of internal habit persistence in households' consumption preferences in the baseline calibration of Kurozumi and Van Zandweghe (2010). The habit persistence weakens the effect of the vacancy channel, since it implies that consumption demand adjusts gradually to changes in the real interest rate, and thus employment can adjust to consumption demand, regardless of the labor market frictions.
} 
response to the contemporaneous inflation rate that meets the Taylor principle increases the real interest rate, but such inflation is dampened by the decline of real marginal cost that results from the rise in the real interest rate. Consequently, the policy rate rise and hence the real interest rate rise are subdued, and thus determinacy and E-stability are guaranteed.

\subsection{The model with both extensive and intensive margins}

As noted above, when labor adjustment takes place solely at the extensive margin, the strictly inflation-forecast targeting interest rate policy that meets the Taylor principle is likely to induce indeterminacy and E-instability of REE. This subsection addresses the question of whether this result is still valid when labor is adjusted at both the extensive and intensive margins. The system of log-linearized equilibrium conditions (20)-(29) is now analyzed.

Under the baseline calibration, the strictly inflation-forecast targeting policy guarantees determinacy of REE for the coefficient interval $1<\phi_{\pi}<1.23$. This interval is somewhat wider than in the absence of variation in hours per worker, but it remains too narrow to include the most empirically plausible values of the coefficient. Thus, the policy responses solely to the inflation forecast that meet the Taylor principle remain likely to induce indeterminacy due to the vacancy channel that arises in the presence of the labor market search and matching frictions. The strictly inflation-forecast targeting policy, however, generates a unique E-stable fundamental REE as long as the Taylor principle is satisfied. Thus, when labor is adjusted at both the extensive and intensive margins, the indeterminacy induced by the strictly inflationforecast targeting policy is not a critical issue from the perspective of E-stability of fundamental REE.

Figure 2 evaluates conditions for determinacy of REE and E-stability of fundamental REE (FREE) on interest rate policy that is flexibly inflation-forecast targeting or contains policy rate smoothing. With a policy response to the inflation forecast that meets the Taylor principle, a sufficiently aggressive policy response to the unemployment forecast or a sufficiently high degree of policy rate smoothing ensures determinacy. With typical values from estimated policy rules, e.g. $\phi_{U}=0.5$ and $\phi_{R}=0.8$ as in line with the estimates by Clarida et al. (2000) for the Volcker-Greenspan period, determinacy is guaranteed. Intuitively, the feedback from the expected future unemployment rate or the past policy rate smoothes the change in the current policy rate in response to a shift in inflation expectations. This dampens the resulting 
change in the real interest rate and hence the change in consumption. Indeed, unemployment rises persistently as a consequence of a rise in the real interest rate stemming from inflationary expectations and hence the negative policy response to the expected future unemployment rate subdues such a rate rise. Moreover, a unique E-stable fundamental REE is generated as long as the Taylor principle is satisfied, regardless of whether the policy responds also to the unemployment forecast or to the past policy rate.

When the policy is outcome-based, adhering to the Taylor principle ensures determinacy and E-stability of REE. This is not surprising, since the same result is obtained in an associated model with a frictionless labor market in which labor is adjusted only at the intensive margin.

\section{Sensitivity analysis regarding values of structural parameters}

This section conducts a sensitivity analysis of determinacy and E-stability regarding values of structural parameters of the model when interest rate policy is strictly inflation targeting, i.e. $\phi_{R}=\phi_{U}=0$ in $(20)$.

The results obtained when the policy $(20)$ is forecast-based (i.e. $i=1$ ) are summarized in Table 2. The first column with results shows how the interval of the policy coefficient $\phi_{\pi}$ that ensures determinacy changes with values of the structural parameters when labor adjustment takes place only at the extensive margin. These results are almost the same as those reported by another paper of ours (Kurozumi and Van Zandweghe, 2010). ${ }^{12}$ As this paper discusses, varying the parameter values affects the upper bound on the determinacy interval in line with the changing effect of the vacancy channel of monetary policy. For instance, the effect of the vacancy channel is strengthened when households' risk aversion is low $(\sigma=0.2)$, since consumption demand becomes more sensitive to the real interest rate. As a result, the upper bound on the determinacy interval becomes smaller. By contrast, high risk aversion $(\sigma=5)$ or high habit persistence $(b=0.8)$ weakens the effect of the vacancy channel and thus increases the upper bound on the determinacy interval. Likewise, a small (large) rate of job destruction implies that employment adjusts slower (faster) to changes in consumption demand, and thus it worsens (mitigates) the effect of the vacancy channel and thereby decreases (increases) the upper bound on the determinacy interval. Further, a high steady-state unemployment rate,

\footnotetext{
${ }^{12}$ The results differ somewhat quantitatively because the baseline calibration of Kurozumi and Van Zandweghe (2010) contains a positive value of habit persistence in consumption preferences.
} 
a low steady-state flow value of unemployment, a low relative bargaining power, a high or low search elasticity of new matches, and a small probability of no price reoptimization all strengthen the effect of the vacancy channel. ${ }^{13}$

The next column shows how the alternative values of the structural parameters affect the two intervals of the policy coefficient on the inflation forecast $\phi_{\pi}$ that generates a unique Estable fundamental REE in the model with the extensive margin only. In most cases, the upper bound on the interval of small policy coefficients that yield the unique E-stable REE shifts in the same direction as the upper bound of the determinacy interval of these policy coefficients. Thus, if an alternative parameter value strengthens the effect of the vacancy channel, the interval of the small policy coefficients becomes narrower. In some cases, this interval disappears entirely, leaving only the interval of large policy coefficients that ensure E-stability (e.g. $\rho=0.07$ and $U=0.1$. In other cases, the upper bound of the interval of the small policy coefficients increases and the interval of policy coefficients inducing E-instability widens sufficiently to eliminate the interval of the large policy coefficients guaranteeing E-stability from the range of policy coefficients under consideration (e.g. $\sigma=5, \rho=0.15, \alpha=0.75) .{ }^{14}$

A shrinking interval of the small policy coefficients that ensure E-stability under alternative values of various structural parameters does not necessarily imply that E-stability becomes less likely, since the intermediate interval of policy coefficients that induce E-instability can also become smaller. Taking this into account, the strictly inflation-forecast targeting interest rate policy that meets the Taylor principle is arguably likely to generate a unique E-stable fundamental REE with empirically plausible responses to the inflation forecast only in the

\footnotetext{
${ }^{13}$ For instance, when $z=0.4$ or $\eta=0.1$ only a policy response that fails to meet the Taylor principle makes determinacy possible. In such a case the effect of the vacancy channel is stronger than that of the demand channel for any policy response to the inflation forecast.

${ }^{14}$ The cases of high habit persistence and a low search elasticity of new matches are exceptions to this pattern. While higher habit persistence increases the upper bound on the determinacy interval, the interval of small policy coefficients that ensure E-stability becomes narrower. Also, a small search elasticity of new matches lowers the upper bound on the determinacy interval but raises the upper bound on the interval of small policy coefficients that guarantee E-stability. As noted by Kurozumi and Van Zandweghe (2010), a small search elasticity of new matches influences the vacancy channel in two opposing ways: it strengthens the effect of the vacancy channel by increasing the sluggishness of employment adjustment (obtained by combining (25) and (26)). But it mitigates the effect by reducing the labor market tightness elasticity of inflation (obtained by combining (21) and (27)) . Thus, these influences may have a different relative importance for determinacy and E-stability.
} 
case of high habit persistence or a small search elasticity of new matches. Taken together, the results of the sensitivity analysis therefore suggest that the strictly inflation-forecast targeting policy is unlikely to guarantee E-stability, in line with the result obtained under the baseline calibration.

The last two columns of Table 2 give comparable intervals of the policy coefficient on the inflation forecast in the model with both the extensive and intensive margins. In terms of determinacy, the results corroborate those obtained with the baseline calibration. A policy coefficient on the inflation forecast that meets the Taylor principle ensures determinacy only if it lies in a narrow interval. Therefore, determinacy is unlikely under the strictly inflationforecast targeting interest rate policy. Moreover, varying values of most structural parameters affects the interval of policy coefficients ensuring determinacy in line with the changing effect of the vacancy channel. In terms of E-stability, the Taylor principle is sufficient to generate a unique E-stable fundamental REE under all the structural parameter values considered. Thus, the sensitivity analysis confirms the E-stability result obtained under the baseline calibration of the model with both the extensive and intensive margins of labor.

Finally, when the strictly inflation targeting interest rate policy is outcome-based (i.e. $i=0$ in (20)), the Taylor principle guarantees determinacy and E-stability under all the alternative values of the structural parameters. ${ }^{15}$

\section{Concluding remarks}

We have examined implications of incorporating labor market search and matching frictions into a sticky price model for determinacy and E-stability of REE under interest rate policy. In the model with the extensive margin only, forecast-based policy that meets the Taylor principle is likely to induce indeterminacy and E-instability, regardless of whether it is strictly or flexibly inflation targeting. This is in contrast to the result of Bullard and Mitra (2002), who use an associated model with a frictionless labor market to show that such forecast-based policy is

\footnotetext{
${ }^{15}$ The determinacy results of the outcome-based policy differ from those reported in Kurozumi and Van Zandweghe (2010), who find that only policy responses without meeting the Taylor principle can induce determinacy under certain calibrations which imply a sluggish adjustment of employment relative to that of consumption. This different result arises because the baseline calibration of Kurozumi and Van Zandweghe (2010) contains a positive value of habit persistence in consumption preferences, whereas the present paper's baseline calibration shown in Table 1 does not.
} 
likely to ensure determinacy of REE and guarantees E-stability of fundamental REE. In the model with both the extensive and intensive margins, the strictly inflation-forecast targeting policy remains likely to induce indeterminacy, but it generates a unique E-stable fundamental REE as long as the Taylor principle is satisfied. These results suggest that introducing the labor market search and matching frictions alter determinacy properties of the strictly inflationforecast targeting policy, but not its E-stability properties in the presence of the intensive margin of labor. Nevertheless, there may exist non-fundamental REE that are also E-stable. We therefore regard the study of E-stability of non-fundamental REE in our model as an important remaining task to be examined in future work. 


\section{References}

[1] Blanchard, O.J., Galí, J., 2010. Labor markets and monetary policy: a new Keynesian model with unemployment. American Economic Journal: Macroeconomics 2, 1-30.

[2] Bullard, J.B., Mitra, K., 2002. Learning about monetary policy rules. Journal of Monetary Economics 49, 1105-1129.

[3] Calvo, G.A., 1983. Staggered prices in a utility-maximizing framework. Journal of Monetary Economics 12, 383-398.

[4] Carlstrom, C.T., Fuerst, T.S., 2004. Learning and the central bank. Journal of Monetary Economics 51, 327-338.

[5] Clarida, R., Galí, J., Gertler, M., 1998. Monetary policy rules in practice: some international evidence. European Economic Review 42, 1033-1067.

[6] Clarida, R., Galí, J., Gertler, M., 2000. Monetary policy rules and macroeconomic stability: evidence and some theory. Quarterly Journal of Economics 115, 147-180.

[7] Evans, G.W., Honkapohja, S., 2001. Learning and Expectations in Macroeconomics. Princeton University Press, Princeton, NJ.

[8] Evans, G.W., McGough, B., 2005. Monetary policy, indeterminacy and learning. Journal of Economic Dynamics and Control 29, 1809-1840.

[9] Faia, E., 2009. Ramsey monetary policy with labor market frictions. Journal of Monetary Economics 56, 570-581.

[10] Hall, R.E., 2009. Reconciling cyclical movements in the marginal value of time and the marginal product of labor. Journal of Political Economy 117, 281-323.

[11] Hall, R.E., Milgrom, P.R., 2008. The limited influence of unemployment on the wage bargain. American Economic Review 98, 1653-1674.

[12] Honkapohja, S., Mitra, K., Evans, G.W., 2003. Notes on agent's behavioral rules under adaptive learning and recent studies of monetary policy. Working paper, University of Helsinki. 
[13] Krause, M.U., Lubik, T.A., 2007. The (ir)relevance of real wage rigidity in the new Keynesian model with search frictions. Journal of Monetary Economics 54, 706-727.

[14] Kurozumi, T., 2006. Determinacy and expectational stability of equilibrium in a monetary sticky-price model with Taylor rule. Journal of Monetary Economics 53, 827-846.

[15] Kurozumi, T., Van Zandweghe, W., 2008. Labor market search and interest rate policy. Research Working Paper 08-03, Federal Reserve Bank of Kansas City.

[16] Kurozumi, T., Van Zandweghe, W., 2010. Labor market search, the Taylor principle, and indeterminacy. Journal of Monetary Economics 57, 851-858.

[17] McCallum, B.T., 1983. On non-uniqueness in linear rational expectations models: an attempt at perspective. Journal of Monetary Economics 11, 139-168.

[18] McCallum, B.T., 1998. Solutions to linear rational expectations models: a compact exposition. Economics Letters 61, 143-147.

[19] McCallum, B.T., 2007. E-stability vis-a-vis determinacy results for a broad class of linear rational expectations models. Journal of Economic Dynamics and Control 31, 1376-1391.

[20] Merz, M., 1995. Search in the labor market and the real business cycle. Journal of Monetary Economics 36, 269-300.

[21] Mortensen, D.T., Pissarides, C.A., 1994. Job creation and job destruction in the theory of unemployment. Review of Economic Studies 61, 397-415.

[22] Orphanides, A., Wieland, V., 2008. Economic projections and rules of thumb for monetary policy. Federal Reserve Bank of St. Louis Review 90, 307-324.

[23] Ravenna, F., Walsh, C.E., 2010. Welfare-based optimal monetary policy with unemployment and sticky prices: a linear-quadratic framework. American Economic Journal: Macroeconomics, forthcoming.

[24] Rannenberg, A., 2009. The Taylor principle and (in-)determinacy in a new Keynesian model with hiring frictions and skill loss. CDMA working paper 09/09, University of St Andrews. 
[25] Sveen, T., Weinke, L., 2009. Inflation and labor market dynamics revisited. Journal of Monetary Economics 56, 1096-1100.

[26] Tang, J.-H., 2010. Optimal monetary policy in a new Keynesian model with job search. Journal of Economic Dynamics and Control 34, 330-353.

[27] Taylor, J.B., 1993. Discretion versus policy rules in practice. Carnegie-Rochester Conference Series on Public Policy 39, 195-214.

[28] Tesfaselassie, M.F., Schaling, E., 2009. On determinacy and learnability in a new Keynesian model with unemployment. Kiel Working Paper 1506, Kiel Institute for the World Economy.

[29] Thomas, C., 2008. Search and matching frictions and optimal monetary policy. Journal of Monetary Economics 55, 936-956.

[30] Trigari, A., 2009. Equilibrium unemployment, job flows and inflation dynamics. Journal of Money, Credit and Banking 41, 1-33.

[31] Van Zandweghe, W., 2010. On-the-job search, sticky prices, and persistence. Journal of Economic Dynamics and Control 34, 437-455.

[32] Walsh, C.E., 2005. Labor market search, sticky prices, and interest rate policies. Review of Economic Dynamics 8, 829-849.

[33] Yun, T., 1996. Nominal price rigidity, money supply endogeneity, and business cycles. Journal of Monetary Economics 37, 345-370. 
Table 1: Quarterly baseline calibration of the model.

\begin{tabular}{lll}
\hline$\beta$ & subjective discount factor & 0.99 \\
$\sigma$ & relative risk aversion & 1 \\
$1 / \mu$ & labor supply elasticity & 0.7 \\
$b$ & internal habit persistence in consumption preferences & 0 \\
$\epsilon$ & elasticity of substitution between retail goods & 10 \\
$\alpha$ & probability of no price reoptimization & 0.67 \\
$h$ & steady-state hours per worker & 1 \\
$U$ & steady-state unemployment rate & 0.06 \\
$z$ & steady-state flow value of unemployment & 0.7 \\
$\eta$ & worker's relative bargaining power & 0.5 \\
$\xi$ & search elasticity of new matches & 0.5 \\
$\rho$ & job destruction rate & 0.1 \\
$\gamma$ & flow cost of vacancy posting & 0.18 \\
$\rho_{g}$ & autoregressive coefficient for consumption preferences shocks & 0.35 \\
\hline
\end{tabular}

Notes: The job destruction rate $(\rho)$ and the steady-state unemployment rate $(U)$ determine the steady-state job finding rate $p$, which is 0.61 under the baseline calibration. The flow cost of vacancy posting $(\gamma)$ is chosen to set the steady-state vacancy filling rate $q$ at a target value, which is 0.7 under the baseline calibration. 
Table 2: Intervals of the coefficient $\phi_{\pi}$ of the strictly inflation-forecast targeting interest rate policy that generates a determinate REE or a unique E-stable fundamental REE.

\begin{tabular}{lllll}
\hline Labor margin & \multicolumn{2}{l}{ Extensive only } & \multicolumn{2}{l}{ Extensive and intensive } \\
Criterion & Determinacy & E-stability & Determinacy & E-stability \\
\hline Baseline & $(1,1.04)$ & $(1,1.34) \cup(13.97, \bar{\phi})$ & $(1,1.23)$ & $(1, \bar{\phi})$ \\
$\sigma=0.2$ & $(1,1.01)$ & $(1,1.06) \cup(3.15, \bar{\phi})$ & $(1,1.08)$ & $(1, \bar{\phi})$ \\
$\sigma=5$ & $(1,1.09)$ & $(1,2.69)$ & $(1,1.38)$ & $(1, \bar{\phi})$ \\
$b=0.8$ & $(1,1.06)$ & $(1,1.01) \cup(1.15, \bar{\phi})$ & $(1,1.40)$ & $(1, \bar{\phi})$ \\
$\rho=0.07$ & $(0.94,1)$ & $(5.88, \bar{\phi})$ & $(1,1.20)$ & $(1, \bar{\phi})$ \\
$\rho=0.15$ & $(1,1.06)$ & $(1,2.50)$ & $(1,1.27)$ & $(1, \bar{\phi})$ \\
$U=0.1$ & $(0.92,1)$ & $(7.42, \bar{\phi})$ & $(1,1.16)$ & $(1, \bar{\phi})$ \\
$z=0.4$ & $(0,1)$ & $(0,1)$ & $(1,1.16)$ & $(1, \bar{\phi})$ \\
$\eta=0.1$ & $(0,1)$ & $(0,1)$ & $(1,1.08)$ & $(1, \bar{\phi})$ \\
$\epsilon=7$ & $(1,1.05)$ & $(1,1.91) \cup(15.36, \bar{\phi})$ & $(1,1.27)$ & $(1, \bar{\phi})$ \\
$\alpha=0.5$ & $(1,1.01)$ & $(1,1.11) \cup(5.26, \bar{\phi})$ & $(1,1.07)$ & $(1, \bar{\phi})$ \\
$\alpha=0.75$ & $(1,1.07)$ & $(1,1.65)$ & $(1,1.45)$ & $(1, \bar{\phi})$ \\
$\xi=0.2$ & $(1,1.02)$ & $(1,9.35)$ & $(1,1.09)$ & $(1, \bar{\phi})$ \\
$\xi=0.7$ & $(0.71,1)$ & $(6.84, \bar{\phi})$ & $(1,1.48)$ & $(1, \bar{\phi})$
\end{tabular}

Note: $\bar{\phi}$ denotes the maximum value of $\phi_{\pi}$ considered in this paper and it is set to 25 . 
Figure 1: Regions of forecast-based policy responses that generate determinacy and E-stability in the model with the extensive margin only.

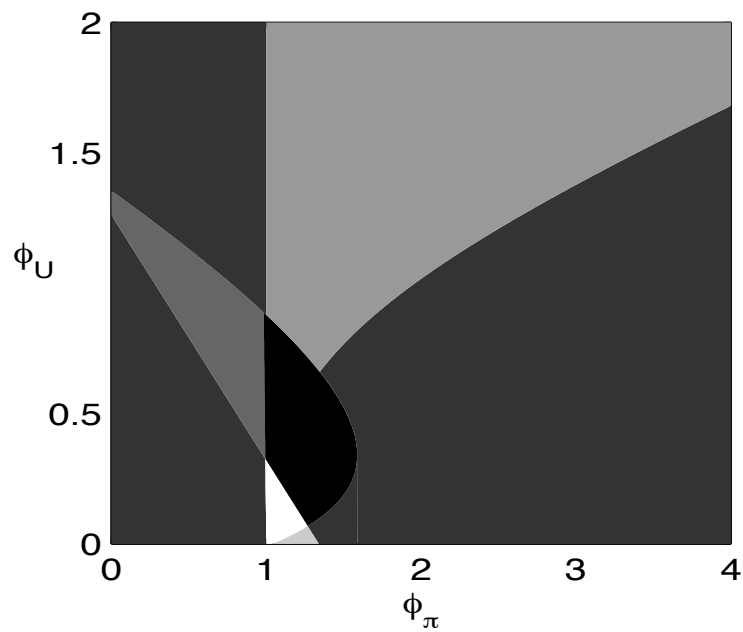

Determinacy \& E-stability

Indet. \& unique E-stable FREE Indet. \& multiple E-stable FREE Determinacy \& E-instability Indeterminacy \& E-instability Nonexistence

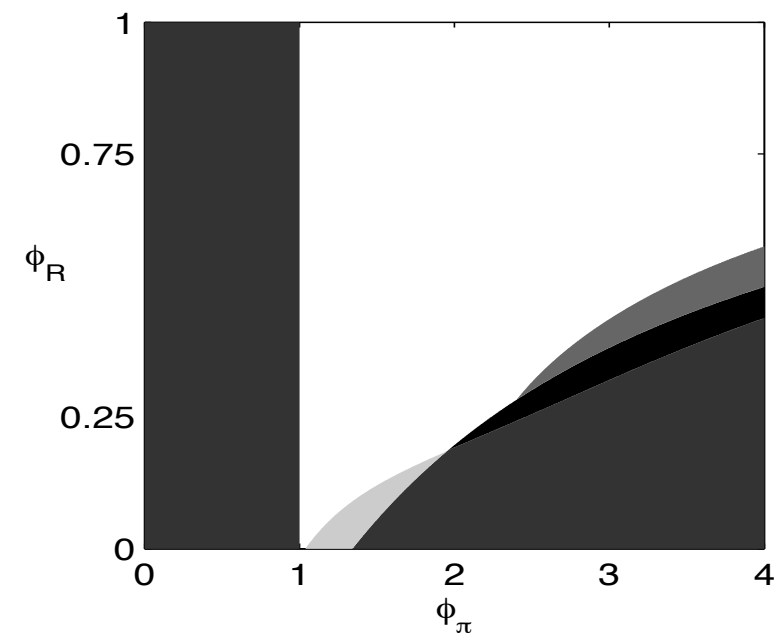


Figure 2: Regions of forecast-based policy responses that generate determinacy and E-stability in the model with both the extensive and intensive margins.

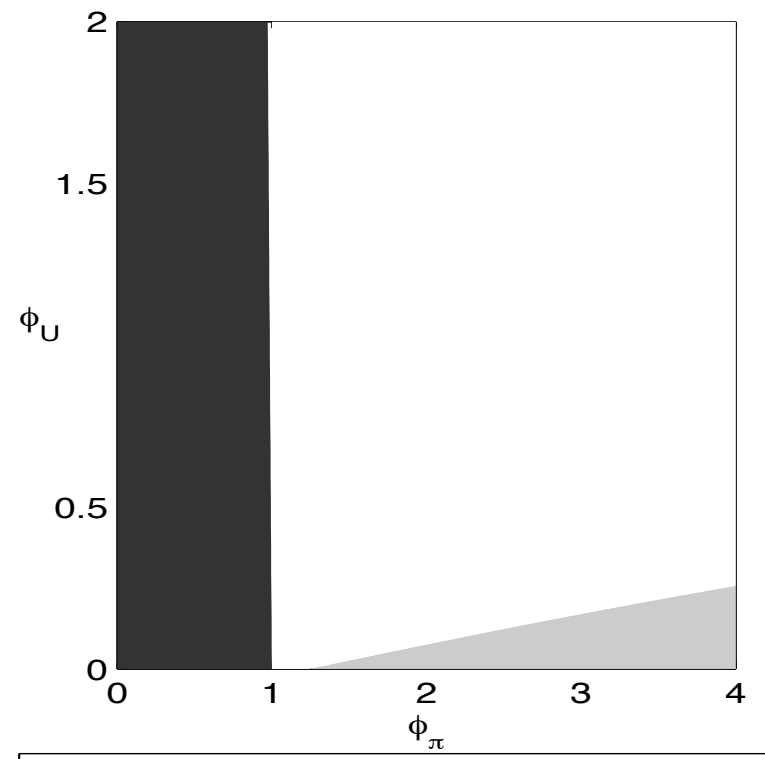

Determinacy \& E-stability

Indeterminacy \& unique E-stable FREE Indeterminacy \& E-instability

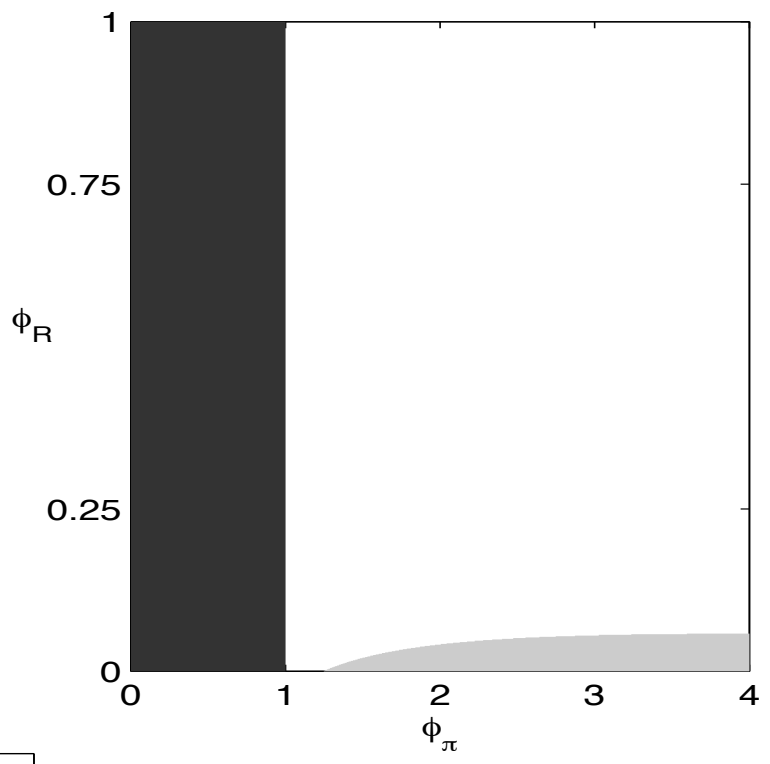

